\title{
MIXED PRICING IN OLIGOPOLY WITH CONSUMER SWITCHING COSTS*
}

\author{
A. Jorge Padilla**
}

WP-AD 91-06

* This paper is a revised version of the third and fourth chapters of my M. PHil Thesis at the University of Oxford. I am grateful to my supervisors Chris Harris and Paul Klemperer for their helpful suggestions. This paper has benefited from the comments of P. Bertoletti, K-U Kuhn, N.H. von der Fehr, J. Fingleton and anonymous thesis examiner, as well as seminar audiences in Barcelona, L.S.E. and the R.E.S. Conference 1991 at Warwick. Financial support from the Bank of Spain and Fundación Ramon Areces is also gratefully acknowledged.

** A.J. Padilla: Nuffield College, Oxford. 


\title{
MIXED PRICING IN OLIGOPOLY WITH CONSUMER SWITCHING COSTS
}

\author{
A. Jorge Padilla
}

\begin{abstract}
In this paper we develop a two-period model of duopolistic competition with consumer switching costs. Our model extends previous results in these kind of models in a more natural framework where products are undifferentiated except by switching costs. We also allow for differently informed consumers and a dynamic consumer turnover. In this model the competitiveness of markets with consumer switching costs is determined by the proportion of price sensitive consumers, that is fully informed uncommitted consumers, in the market. In contrast with previous studies, firms have different (asymmetric) market shares in equilibrium. Our model supports the presence of action-reaction in the evolution of markets with consumer switching costs, the possibility of (accidental) price wars, price promotions, and the possible optimality of strategic commitment to a low market share as a way to deter entry in this type of market.
\end{abstract}

JEL nos. 022. 611

Keywords: Market share, mixed strategies, switching costs. 


\section{Introduction}

Consumer switching costs have been the focus of much attention in recent years. They are the costs consumers face when switching suppliers, as for example the costs of changing a current account from one bank to another. Switching costs lock consumers into the firms they were previously patronizing. Consequently, we can distinguish between locked-in and uncommitted consumers. The simultaneous presence of these two types of consumers, together with the inability of firms to price discriminate among them, has important implications for the competitiveness of markets. Switching costs models are also of theoretical interest as a result of their ability to explain market inertia. These models because of the importance placed on market share and long-run profitability, provide an explanation to the observed behaviour of managers who seem more concerned with market share than with short-run profitability ${ }^{1}$.

The two-period model we develop in this paper is able to reproduce in a simple model where products are undifferentiated except by switching costs, many of the existing (but dispersed) results in the literature. It also clarifies the main forces driving competition in one or another direction i.e., towards full collusive or more competitive outcomes. More importantly, we extend previous results in several directions. In particular, market structures where ex-ante identical firms have ex-post asymmetric market shares are found in equilibrium. We also find some support for action-reaction dynamics in the evolution of markets with switching costs, and the possibility of equilibrium stochastic (accidental) price wars.

The basic model is extended to analyze growing demand, entry deterrence and finally, the implications of different mechanisms of information gathering on our main results. More precisely, we ask how first and second period competition are affected 
when demand grows over time. We find that while second period prices are lower, the effect on first period prices is ambiguous. We also show how incumbent firms may deter entry by committing to a lower market share in the pre-entry period. Finally, when the informational setting is modified to consider word-of-mouth externalities, the results of previous sections are reinforced.

Our model differs from previous two-period models of consumer switching costs on several grounds. While most models assume differentiated products (von Weizsacker 1984, Klemperer 1987b), we consider ex-ante homogenous products only differentiated ex-post by switching costs. Our model includes a dynamic consumer turnover which differentiates it from similar models e.g. Klemperer [1987a]. In particular, Klemperer [1987a] cannot cope with new consumers in every period, while Klemperer [1987b] achieves this only by incorporating real (functional) product differentiation. More importantly, our model is the first to study structures in which asymmetric market shares result in markets with consumer switching costs.

This paper is organized as follows. Section II presents the model and discusses the assumptions. Sections III and IV are devoted to solving the model for the second period and the overall game respectively. Section $\mathrm{V}$ provides interpretations of the results of previous sections. It concentrates on the competitiveness of markets with consumer switching costs, on the existence of price wars and sales, and on the evolution of this type of markets. Section VI extends the model to deal with growing demand, entry and finally, the implications of word-of-mouth externalities. Section VII concludes. 


\section{The model}

We consider a duopolistic market in which two firms produce an identical, non-storeable good with identical constant marginal cost without loss of generality equal to zero. Risk-neutral firms set prices simultaneously and independently in each of two periods, where the second period is discounted with discount factor $0 \leq \delta \leq 1$.

There are $\mathrm{N}$ consumers, each with unit inelastic demand with reservation price $\mathrm{p}_{\mathbf{r}}$ in each period. Consumers are assumed to only care about the price to be paid in the current period. Consumers also have (exogenous) switching costs, that is, once a consumer has bought from either firm, he is locked-in. These costs are large enough to deter any switching.

Consumers are differently informed about market supply. Some consumers are informed about the price offers of the two firms while others are only informed about one of these offers. Let $\phi \in[0,1]$ be the proportion of fully informed consumers, with $(1-\phi) / 2$ being the proportion of consumers only informed of firm j's offer, $j=1,2$.

The two periods are linked by a dynamic consumer flow. At the end of the first period each consumer has a positive probability $\mu$ of leaving the market. Such an outflow is offset by an inflow of new (uncommitted) consumers so that the final number of consumers in the market is in steady state.

In period one, firms set prices and then consumers allocate themselves among firms. A consumer will buy a unit of the good as long as the price he faces is lower or equal to the reservation price. While fully informed consumers buy from the lowest priced firm, partially informed consumers buy from the firm about which they are informed. In 
period two, given first period market shares, firms set prices and subsequently new (uncommitted) consumers choose where to buy according to their respective information. Locked-in consumers who remain in the market continue buying from the firm they were patronizing in period one. Firms cannot price discriminate between uncommitted and locked-in consumers.

\section{The second period subgame}

Let us denote by $x_{j t}$ the number of consumers buying from firm $j$ at $t, t=1,2$. (Thus, $x_{j t} / N$ defines the market share of firm $j$ at $t$.) In period two given the market shares of the two firms at the end of the previous period, firms set prices to maximize currently expected profits. We denote by $p_{j t}$ the price charged by firm $j$ in period $t, p_{j t}$, and by $\Pi_{j t}$ the expected profits of firm $j$ at $t$. Once firms have set their respective prices, the outflow and inflow of consumers take place. Finally, new uncommitted consumers allocate themselves among firms. There are three different kinds of consumers coexisting in the market in period two. Old or locked-in consumers; new consumers only informed from one firm and, new fully informed consumers. Given the definitions of $\mu$ and $\phi$ above and the fact that the number of consumers is in steady state, the proportions of old consumers, new partially informed consumers, and new fully informed consumers are $(1-\mu),(1-\phi) \mu$ and $\mu \phi$ respectively.

Given $\mathrm{x}_{11}, \mathrm{x}_{21}$ (respectively the number of consumers buying from firms 1 and 2 in period one), equation (1) represents the current expected profits of firm $j$ in period two. Note that both firms equally share the market when their prices coincide. (It will become evident that for the second period subgame the specific rule used to allocate demand among firms when there is a tie will have no effect on any of our results.) 


$$
\begin{gathered}
\Pi_{\mathrm{j} 2}\left(\mathrm{p}_{\mathrm{j} 2}\right)=\mathrm{p}_{\mathrm{j} 2}\left[(1-\mu) \mathrm{x}_{\mathrm{j} 1}+\mu(1-\phi) \mathrm{N} / 2\right] \quad \text { if } \mathrm{p}_{\mathrm{j} 2}>\mathrm{p}_{\mathrm{k} 2} \\
=\mathrm{p}_{\mathrm{j} 2}\left[(1-\mu) \mathrm{x}_{\mathrm{j} 1}+\mu \mathrm{N} / 2\right] \quad \text { if } \mathrm{p}_{\mathrm{j} 2}=\mathrm{p}_{\mathrm{k} 2} \\
=\mathrm{p}_{\mathrm{j} 2}\left[(1-\mu) \mathrm{x}_{\mathrm{j} 1}+\mu(1+\phi) \mathrm{N} / 2\right] \quad \text { if } \mathrm{p}_{\mathrm{j} 2}<\mathrm{p}_{\mathrm{k} 2} \\
\mathrm{j}, \mathrm{k}=1,2 ; \mathrm{j} \neq \mathrm{k} \text { and } \mathrm{p} \leq \mathrm{p}_{\mathrm{r}}
\end{gathered}
$$

We deal with the non-trivial case where $\mu, \phi \in(0,1)$, so that there are consumers from each of the three types we mentioned above. We first show that under these conditions, there is no equilibrium in pure strategies and second, that a mixed strategy equilibrium does exists and has very intuitive properties ${ }^{34}$. (All proofs can be found in the appendix.)

Lemma 1. For all $\mu, \phi \in(0,1)$ and for all given $x_{11}, x_{21}$, there is no $N E$ in pure strategies for the second period subgame.

We shall find two distribution functions $\xi_{12}(\mathrm{p})$ and $\xi_{22}(\mathrm{p})$ representing the pricing strategies of firms 1 and 2 respectively. $\xi_{j 2}$ gives the probability that firm $j$ charges a price smaller than p. Recall that the support of a probability distribution is the smallest closed set with probability one. Let $\operatorname{supp} \xi_{\mathrm{j} 2}$ be the support of $\xi_{\mathrm{j} 2}$ with $\mathrm{p}_{\mathrm{j} 2}$ ' $\overline{\mathrm{p}}_{\mathrm{j} 2}$, being its lower and upper bounds respectively. In equilibrium, firm $\mathrm{j}$ has to be indifferent between all prices in its support. Finally, $\zeta_{j 2}=\partial \xi / \partial \mathrm{p}$ almost everywhere.

In what follows we assume $x_{11} \geq x_{21}$ without loss of generality. Currently expected profits can be rewritten as,

$$
\Pi_{j 2}(p)=p\left[(1-\mu) x_{j 1}+\mu\left((1-\phi) / 2+\phi\left(1-\xi_{k 2}(p)\right) N\right] k, j=1,2 k \neq j .\right.
$$


Definition: A pair of distribution functions $\left(\xi_{12}, \xi_{22}\right)$ is said to be a NE if and only if for all $j$, given $\xi_{k 2}(p) k \neq j, \Pi_{j 2}(p)$ is equal to $\pi_{j 2}$ a constant, for all $p$ in $\operatorname{supp} \xi_{\mathrm{j} 2}$, and not greater than $\pi_{\mathrm{j} 2}$ for any $\mathbf{p}$.

We can then prove the following lemmata:

Lemma 2. $\quad \bar{p}_{j 2} \leq p_{r} j=1,2$ (i.e., $\zeta_{j 2}(p)=0$ for $p>p_{r} j=1,2$.)

Lemma 3. $\quad \underline{\mathrm{p}}_{\mathrm{j} 2} \geq \hat{\mathrm{p}}_{\mathrm{j} 2}=\mathrm{p}_{\mathrm{r}}\left[(1-\mu) \mathrm{x}_{\mathrm{j} 1}+\mu(1-\phi) \mathrm{N} / 2\right] /\left[(1-\mu) \mathrm{x}_{\mathrm{j} 1}+\mu(1+\phi) \mathrm{N} / 2\right]<\mathrm{p}_{\mathrm{r}}$ $\mathrm{j}=1,2$ (i.e., $\zeta_{\mathrm{j} 2}(\mathrm{p})=0$ for $\mathrm{p}<\hat{\mathrm{p}}_{\mathrm{j} 2}$ )

where $\hat{p}_{j 2}$ is the lowest price firm $\mathrm{j}$ is willing to pay in order to be the lowest priced firm. In other words, given that firm $\mathrm{j}$ cannot price discriminate between locked-in and uncommitted consumers, this is the price, $p$, that makes the firm indiferent between only selling to locked-in consumers at the reservation price $p_{r}$, and selling to all consumers at $\mathbf{p}$.

Lemma 4. Suppose that either $\overline{\mathrm{p}}_{12}>\overline{\mathrm{p}}_{22}$, or that $\overline{\mathrm{p}}_{12}=\overline{\mathrm{p}}_{22}$ and $\overline{\mathrm{p}}_{22}$ is not named with positive probability. Then, in any equilibrium,

(a) $\overline{\mathrm{p}}_{12}=\mathrm{p}_{\mathrm{r}}$ and the equilibrium profits of firm 1 are given by $\hat{\mathrm{p}}_{12}\left[(1-\mu) \mathrm{x}_{11}+\mu(1+\phi) \mathrm{N} / 2\right]$

(b) $\underline{\mathrm{p}}_{12}=\underline{\mathrm{p}}_{22}=\underline{\mathrm{p}}$ and neither of them was named with positive probability

(c) $\underline{\mathrm{p}}=\hat{\mathrm{p}}_{12}$

(d) $x_{11} \geq x_{21}$

(e) The equilibrium level of profits of firm 2 is uniquely determined by $\left(\mathrm{x}_{11}, \mathrm{x}_{21}\right)$ and it is equal to $\underline{\mathrm{p}}\left[(1-\mu) \mathrm{x}_{21}+\mu(1+\phi) \mathrm{N} / 2\right]$. 
Lemma 4 tells us what are the basic properties that have to be satisfied by the respective supports of any pair of equilibirum strategies. It also tell us what are the expected profits of each firm in such an equilibrium ${ }^{5}$. Therefore, from Lemma 4

$$
\begin{gathered}
\pi_{\mathrm{j} 2}=\Pi_{\mathrm{j} 2}(\underline{\mathrm{p}})=\underline{\mathrm{p}}\left[(1-\mu) \mathrm{x}_{\mathrm{j} 1}+\mu(1+\phi) \mathrm{N} / 2\right] \\
\underline{\mathrm{p}}=\mathrm{p}_{\mathrm{r}} \frac{(1-\mu) \mathrm{x}_{11}+\mu(1-\phi) \mathrm{N} / 2}{(1-\mu) \mathrm{x}_{11}+\mu(1+\phi) \mathrm{N} / 2}
\end{gathered}
$$

In equilibrium, $\Pi_{j 2}(p)=\pi_{j 2}$ for all $p$ in the support of $\xi_{j 2}$ for all $j$, or alternatively,

$$
\begin{gathered}
\Pi_{\mathrm{j} 2}(\mathrm{p})=\mathrm{p}\left[(1-\mu) \mathrm{x}_{\mathrm{j} 1}+\mu\left((1-\phi) / 2+\phi\left(1-\xi_{\mathrm{k} 2}(\mathrm{p})\right)\right) \mathrm{N}\right] \\
=\underline{\mathrm{p}}\left[(1-\mu) \mathrm{x}_{\mathrm{j} 1}+\mu(1+\phi) \mathrm{N} / 2\right] \mathrm{k}, \mathrm{j}=1,2 \mathrm{k} \neq \mathrm{j}
\end{gathered}
$$

It is easy to see that $\Pi_{12} \geq \Pi_{22}$ for all $p$, that is current expected profits in the second period are larger for the firm with the larger market share in the first period. This finding makes it clear why market share is important. Notice that total industry profits, as implicitly defined in (3), are increasing in the degree of asymmetry in market share or i.e., in the difference $x_{11}-x_{21}$. If firms were allowed to collude they would exploit this fact by rearranging production between themselves. In this sense, for instance, mergers to monopoly are always profitable in this type of markets. However, Padilla [1990b] shows that mergers may not be privately profitable in this type of markets if they do not involve the whole industry. 
Solving the system of equations in (3) we obtain,

(4) $\xi_{\mathrm{j} 2}(\mathrm{p})=\frac{(\mathrm{p}-\underline{\mathrm{p}})\left[(1-\mu) \mathrm{x}_{\mathrm{k} 1}+\mu(1+\phi) \mathrm{N} / 2\right]}{\mathrm{p} \mu \phi \mathrm{N}} \mathrm{k}, \mathrm{j}=1,2 \mathrm{k} \neq \mathrm{j}$

where $\xi_{12}(\mathrm{p}) \leq \xi_{22}(\mathrm{p})$ when $\mathrm{x}_{11} \geq \mathrm{x}_{21}$ and $\xi_{12}(\mathrm{p}) \equiv \xi_{22}(\mathrm{p})$ when $\mathrm{x}_{11}=\mathrm{x}_{21}$. That is, $\xi_{12}$ stochastically dominates $\xi_{22}$ whenever firm 1 is the largest firm. This is an intuitive result because it indicates that the larger firm will charge higher prices with larger probability than the smallest firm. Finally, we have to check that $\xi_{12}, \xi_{22}$ are proper cumulative distribution functions satisfying Lemma 4 . We do so in four steps.

(a) $\xi_{j 2}(p)=0$. Both functions begin at the infimum of the support.

(b) $\zeta_{j 2}(p)=\frac{(1-\mu) x_{k 1}+\mu(1+\phi) N / 2}{\mu \phi N}\left(\underline{p} / p^{2}\right)>0$ for all $j, k j \neq k$. Thus $\xi_{j 2}$ is strictly increasing on the support. Note in addition, that $\xi_{\mathrm{j} 2}$ is concave for all $\mathrm{j}$.

(c) $\xi_{22}\left(\mathrm{p}_{\mathrm{r}}\right)=\frac{(1-\mu) \mathrm{x}_{11}+\mu(1+\phi) \mathrm{N} / 2}{\mu \phi \mathrm{N}_{\mathrm{r}}}\left(\mathrm{p}_{\mathrm{r}}-\underline{\mathrm{p}}\right)=1$

(d) $\xi_{12}\left(\mathrm{p}_{\mathrm{r}}\right)=\frac{(1-\mu) \mathrm{x}_{21}+\mu(1+\phi) \mathrm{N} / 2}{\mu \phi \mathrm{Np}_{\mathrm{r}}}\left(\mathrm{p}_{\mathrm{r}}-\mathrm{p}\right)<1$ when $\mathrm{x}_{21}<\mathrm{x}_{11}$

$$
=1 \text { when } \mathrm{x}_{21}=\mathrm{x}_{11} \text {. }
$$

From (b), firm j's second period expected prices $\mathrm{Ep}_{\mathrm{j} 2}$ are,

$$
\mathrm{Ep}_{22}=\mathrm{A}_{2} \underline{\mathrm{p}} \ln \left(\mathrm{p}_{\mathrm{r}} / \underline{\mathrm{p}}\right)>0 ; \mathrm{Ep}_{12}=\mathrm{A}_{1} \underline{\mathrm{p}} \ln \left(\mathrm{p}_{\mathrm{r}} / \underline{\mathrm{p}}\right)+\mathrm{p}_{\mathrm{r}} \aleph\left(\mathrm{p}_{\mathrm{r}}\right)>\mathrm{Ep}_{22}>0
$$


where $\mathrm{A}_{\mathrm{j}}=\left[(1-\mu) \mathrm{x}_{\mathrm{k} 1}+\mu(1+\phi) \mathrm{N} / 2\right] / \mu \phi \mathrm{N}$ j, $\mathrm{k}=1,2 \mathrm{j} \neq \mathrm{k}$, and $\aleph\left(\mathrm{p}_{\mathrm{r}}\right)$ is the probability mass at the atom in the pricing strategy of firm $1, \aleph\left(\mathrm{p}_{\mathrm{r}}\right)=1-\xi_{12}\left(\mathrm{p}_{\mathrm{r}}\right)>0$.

[Insert figure 1]

The following proposition summarizes our results,

Proposition 1. (EXISTENCE) If $\mathrm{x}_{11} \geq \mathrm{x}_{21}$ for all $\mu, \phi \in(0,1)$, there is a mixed strategy equilibrium for the second-period subgame. Moreover that equilibrium has the following properties: each firm set prices according to continuous and strictly increasing distribution functions over a coincident interval, except that firm 1 names the uppermost price with positive probability whenever $\mathrm{x}_{11}>\mathrm{x}_{21}$, and finally, $\xi_{12}(\mathrm{p}) \leq \xi_{22}(\mathrm{p})$, i.e., firm 1's strategy stochastically dominates the strategy of firm 2 , with strict inequality when $x_{11}>x_{21}$.

It is interesting to notice the presence of an atom of positive probability in the distribution function of the larger firm. Notice in particular that the density of such an atom, $\aleph\left(p_{r}\right)$ is an increasing function of the degree of asymmetry in market share in the first period. This is because the more asymmetric the market, the more tempted the larger firm is to exploit its locked-in consumers giving up competition for uncommitted consumers. It is this property which supports action-reaction in market share. Further comments on action-reaction, and more in general, on the evolution of industry with consumer switching costs are postponed to section V.2.

Corollary 1. If $x_{11} \geq x_{21}$ then, any possible equilibria of the second period subgame is characterized by the same level of expected profits for each firm. 
Proposition 2. (UNIQUENESS) If $x_{11} \geq x_{21},\left(\xi_{12}, \xi_{22}\right)$ is the unique NE of the second period subgame, (with $\xi_{\mathrm{j} 2}$ given in equation (4) above.)

\section{Equilibria in the full game}

In the previous section we found and characterized the unique equilibrium for the second period subgame given the market shares of the first period. In this section we concentrate precisely on the first period when such market shares have to be determined. Consumers have naive expectations, so that they do not take into account the second period when making first-period decisions. On the other hand, firms maximized currently discounted expected profits, (Firms have a common discount factor $\delta$, $0 \leq \delta \leq 1$.) Hence, firm $\mathrm{j}$ names $\mathrm{p}_{\mathrm{j} 1}$ to maximize (5) below subject to $\Pi_{\mathrm{j}} \geq 0$ and $\mathrm{p}_{\mathrm{j} 1} \leq \mathrm{p}_{\mathrm{r}}$ for all $\mathrm{j}$.

$$
\Pi_{\mathrm{j}}\left(\mathrm{p}_{11}, \mathrm{p}_{21}\right)=\Pi_{\mathrm{j} 1}\left(\mathrm{p}_{11}, \mathrm{p}_{21}\right)+\delta \Pi_{\mathrm{j} 2}\left(\mathrm{x}_{\mathrm{j} 1}\left(\mathrm{p}_{11}, \mathrm{p}_{21}\right)\right)
$$

Note that now, in addition to $\mathrm{p}$ lower than the reservation price we require total profits to be positive, otherwise the firm would simply leave the market. In this period all consumers are uncommitted in the sense that none of them is locked-in. We consider the case where $\phi \in(0,1)$ that is some consumers are fully informed whereas others are only partially informed. As in the second period subgame there is no equilibrium in pure strategies. However, there is a unique equilibrium in mixed strategies. We first show the existence of a symmetric equilibrium by means of a constructive argument. Looking for symmetric equilibrium seems the natural procedure 
given the symmetric structure of the full game. Then, we prove that this is indeed the unique equilibrium of this game.

From section III we know that the expected level of profits in the second period is given by $\pi_{\mathrm{j} 2}=\underline{\mathrm{p}}\left[(1-\mu) \mathrm{x}_{\mathrm{j} 1}+\mu(1+\phi) \mathrm{N} / 2\right]$ for all $\mathrm{j}$. If we denote by $\mathrm{x}^{*}$ the maximum of $\mathbf{x}_{11}, \mathbf{x}_{21}$, the infimum of the support of $\xi_{j 2} j=1,2$ is equal to,

$$
\underline{\mathrm{p}}=\mathrm{p}_{\mathrm{r}} \frac{(1-\mu) \mathrm{x}^{*}+\mu(1-\phi) \mathrm{N} / 2}{(1-\mu) \mathrm{x}^{*}+\mu(1+\phi) \mathrm{N} / 2}
$$

The number of consumers buying from firm $\mathrm{j}$ in period 1 can take three different values, $(1-\phi) \mathrm{N} / 2, \mathrm{~N} / 2,(1+\phi) \mathrm{N} / 2$ depending on whether firm $\mathrm{j}$ fails to be the lowest priced firm, there is a tie with both firms naming the same price, or firm $\mathrm{j}$ succeds in being the lowest priced firm. Therefore, $x^{*}$ is either $N / 2$ or $(1+\phi) N / 2$ and $p$ takes only one of the two following values, denoted by $\mathrm{p}^{\prime}$ and $\mathrm{p}^{\prime \prime}$ respectively. $\mathrm{p}^{\prime}=\mathrm{p}_{\mathrm{r}} \frac{1-\mu \phi}{1+\mu \phi}$, $\mathrm{p}^{\prime \prime}=\mathrm{p}_{\mathrm{r}} \frac{(1+\phi)-2 \mu \phi}{(1+\phi)}$, where p" $>$ p'. Then total discounted profits in (5) are equal to,

$$
\begin{gathered}
\Pi_{j}=p_{j 1}(1-\phi) N / 2+\delta p^{\prime \prime}[(1-\mu)(1-\phi)+(1+\phi) \mu] N / 2 p_{j 1}>p_{k 1} \\
=p_{j 1} N / 2+\delta p^{\prime}(1+\mu \phi) N / 2 p_{j 1}=p_{k 1} \\
=p_{j 1}(1+\phi) N / 2+\delta p^{\prime \prime}(1+\phi) N / 2 p_{j 1}<p_{k 1} \\
\forall k, j j \neq k
\end{gathered}
$$

Lemma 6. For $\phi \in(0,1), 0 \leq \delta \leq 1$, there is no $\mathrm{NE}$ in pure strategies for the full game. 
Denote by $\mathrm{p}^{*}$ the minimum price each firm is willing to pay in order to serve to all informed consumers in the market. Then $\mathrm{p}^{*}$ is such that,

$$
(1+\phi)\left(\mathrm{p}+\delta \mathrm{p}^{\prime \prime}\right)=(1-\phi) \mathrm{p}_{\mathrm{r}}+\delta \mathrm{p}^{\prime \prime}[(1-\mu)(1-\phi)+(1+\phi) \mu]
$$

and hence,

$$
\mathrm{p}^{*}=\left[(1-\phi) \mathrm{p}_{\mathrm{r}}-2 \delta \mathrm{p}^{\prime \prime} \phi(1-\mu)\right] /(1+\phi)^{6}
$$

Let $\Pi_{f}(p)$ be the level of profits obtained by a firm charging price $p$ and failing to be the lowest priced firm, and $\Pi_{s}(p)$ the profits of a firm when it succeds in being the lowest priced firm. Then, total discounted profits can be written as,

$$
\begin{aligned}
& \Pi_{j}(p)=\Pi_{f}(p) \Omega(p)+\Pi_{s}(p)(1-\Omega(p)) \\
& =(1-\Omega(p))\left(\Pi_{s}(p)-\Pi_{f}(p)\right)+\Pi_{f}(p)
\end{aligned}
$$

where $\Omega(p)$ represents the pricing strategy of each firm in a symmetric equilibrium. $(\Omega(p)$ is a cumulative distribution function.) The corresponding density function is represented by $\omega(\mathrm{p}) \quad\left(\omega(\mathrm{p})=\Omega^{\prime}(\mathrm{p})\right)$ almost everywhere. Notice that there is a zero probability of a tie, or in other words that no symmetric equilibrium can be characterized by pricing strategies involving mass points (a formal proof of this statement can be found in Lemma 9.1 in the appendix.)

As we formally stated in the previous section, a pair of distributions $(\Omega(\mathrm{p}), \Omega(\mathrm{p}))$ constitutes a (symmetric) NE if given that firm $\mathrm{k} \neq \mathrm{j}$ names prices according to $\Omega(\mathrm{p})$, $\Pi_{j}(p)$ is equal to a constant $\pi$ for all $p$ in the support of $\Omega(p)$, and not greater than $\pi$ for any p. We can now prove the following lemmas, 
Lemma 7. If $\Omega(p)$ is a NE distribution function, then $\omega(p)=0$ for $p>p_{r}$.

Lemma 8. If $\Omega(\mathrm{p})$ is a $\mathrm{NE}$ distribution function, then $\overline{\mathrm{p}}$ the supremum of the support of $\Omega(p)$, is equal to the reservation price $p_{r}$.

From Lemma 8, profits in a NE are equal to

(9)

$$
\pi=\Pi_{\mathrm{f}}\left(\mathrm{p}_{\mathrm{r}}\right)=\left\{(1-\phi) \mathrm{p}_{\mathrm{r}}+\delta \mathrm{p}^{\prime \prime}[(1-\mu)(1-\phi)+(1+\phi) \mu]\right\} \mathrm{N} / 2
$$

Therefore,

(10) $\quad \Omega(p)=1-\frac{\Pi_{\mathrm{f}}\left(\mathrm{p}_{\mathrm{r}}\right)-\Pi_{\mathrm{f}}(\mathrm{p})}{\Pi_{\mathrm{s}}(\mathrm{p})-\Pi_{\mathrm{f}}(\mathrm{p})}=1-\frac{(1-\phi)\left(\mathrm{p}_{\mathrm{r}}-\mathrm{p}\right)}{2 \phi\left(\mathrm{p}+\delta \mathrm{p}^{\prime},(1-\mu)\right)}$

Finally, we need to check that $\Omega(p)$ is a proper distribution function and that $p_{r}$ is effectively the supremum of the support. We proceed in three steps. (a) $\Omega\left(\mathrm{p}_{\mathbf{r}}\right)=1$ as we can easily observe by substituting $p_{r}$ into (10); (b) $\omega(p)=\Omega^{\prime}(p) \geq 0$ for all $p$ in the support of $\Omega(\mathrm{p})$. Hence $\Omega(\mathrm{p})$ is increasing, and it is also easy to see that is concave i.e., $\omega^{\prime}(\mathrm{p})<0$ for all $\mathrm{p}$; finally, (c) $\Omega\left(\mathrm{p}^{*}\right)=0$ and therefore $\mathrm{p}^{*}$ as defined above is the infimum of the support of $\Omega(\mathrm{p})$, or in other words is the largest price such that $\Omega(\mathrm{p})$ is equal to zero.

The following propositions summarize the results of this section, 
Proposition 3. (EXISTENCE) For $\phi \in(0,1), 0 \leq \delta \leq 1$, there is a symmetric mixed strategy equilibrium for the full game. Furthermore, $\Omega(p)$ represents the pricing strategies of both firms in such an equilibrium. $\Omega(\mathrm{p})$ is a cumulative distribution function beginning at zero when $p=p^{*}$, increasing for all $\mathrm{p} \in\left[\mathrm{p}^{*}, \mathrm{p}_{\mathrm{r}}\right]$ and with value one at $\mathrm{p}_{\mathrm{r}}$.

[Insert figure 2]

Proposition 4. (UNIQUENESS) For $\phi \in(0,1),(\Omega(\mathrm{p}), \Omega(\mathrm{p}))$ is the unique equilibrium for the first period (overall) game.

\section{The nature of competition}

In this section we give some interpretations for our previous results. In particular, we focus on the degree of competitiveness, on the existence of stochastic price wars and sales, and on the evolution of market structure.

\section{V.1. The degree of competitiveness}

For the second period, it is easy to characterize the limiting results of our model. When either $\mu$ or $\phi$ are set equal to zero, that is, when no consumer turnover takes place and/or all consumers are imperfectly informed by both firms, the two firms charge the monopoly price. On the other hand, when every consumer in the second period is uncommitted and fully informed $(\mu=\phi=1)$, we obtain the typical Bertrand competition outcome without capacity constraints. Note that as $\mu$ becomes larger the 
importance of switching costs is reduced. In particular, the case of $\mu=1$ can be understood as the absence of switching costs.

In the non-trivial case (i.e., when $\mu, \phi \in(0,1))$, the importance of market share in markets with consumer switching costs is made clear by the fact that second period expected profits are larger the larger the first period market share. The equilibrium described is asymmetric unless both firms have identical initial market shares (which happens with probability zero.) The larger firm sets higher prices with larger probability, or in other words, the distribution function representing the pricing strategy of the larger firm stochastically dominates that of the smaller firm. Even more, the larger firm charges the uppermost price with positive probability. In conclusion, competition in the second period yields outcomes between full collusion and Bertrand competition, where we approach one or another extreme depending on the number (proportion) of price sensitive consumers in the market (i.e., $\mu \phi$.) When $\mu \phi$ approaches zero, collusive outcomes obtain, when it is equal to one the result is that of Bertrand competition. In between prices are random but in expected terms competitiveness is reduced by switching costs. Switching costs have the final effect of making the demand faced by each firm more inelastic and thus of increasing each firm's monopolistic power. Notice in particular, that these results are valid for all $\phi \in(0,1)$. Though the existence of uninformed consumers can cause by itself a fall in the degree of competitiveness our general result, switching costs relax second period competition, is valid even when all consumers are fully informed ${ }^{7}$. Finally, it is interesting to observe that overall industry profits are larger the larger is the asymmetry between firms' market shares. This observation, together with the results of section VI.3, imply that the number of firms in the market is not the main determinant of the profitability of a particular industry. It is precisely the degree of asymmetry in firms' market shares which constitutes the crucial factor in the determination of overall industry profits and consumer welfare. 
In the first period, competition can be shown to be, in general, fiercer than in the second period. Firms want to obtain a large market share today, since this means larger expected profits next period. However, the presence of price-insensitive (uninformed) consumers may moderate competitiveness in such a way that no definitive conclusion can be established for all values of $\mu$ and $\phi$. An increase in the proportion of locked-in consumers in the second period (a decrease in $\mu$ ) leads to lower expected prices. In fact, as $\mu$ approaches zero expected prices fall below marginal cost. In addition, given that $\phi$ is kept constant over both periods, price competition is necessarily more severe in the first period whenever there is a positive proportion of locked-in consumers in the second period. In conclusion, while switching costs clearly relax second-period competition, they lead to fiercer competition in the first period. Thus the overall competitive effect has to be evaluated through the analysis of the net effect of switching costs on total profits. Total profits, $\pi$, are given in equation (9). From (9), $\partial \pi / \partial \mu>0(<0)$ if and only if $\mu<1 / 2(>1 / 2)$. That is, starting from a situation of no switching costs $(\mu=1)$, these costs necessarily relax overall competition. However, when switching costs are too large, then competition in the first period becomes strong enough to make the market relatively more competitive than an otherwise identical market without switching costs.

Our model can be also regarded as an equilibrium model of price dispersion with ex-ante identical consumers. Price dispersion arises as a consequence of two types of ex-post differentiation; firms are ex-post differentiated because the presence of switching costs, and consumers are ex-post differentiated because of the random mechanism that determines the information endowment of each consumer. 


\section{V.2. The evolution of market structure}

The evolution of market structure has been the subject of some recent studies, e.g. Harris [1988] and Budd et al.[1990]. From these models it seems clear that in most cases the natural evolution for market structure is characterized by increasing dominance, that is, by a tendency towards more asymmetric structures. It is nevertheless possible to construct examples in which the evolution of market structure is characterized by continuous changes in market leadership or more generally by the lack of persistence of dominant positions in the market, that is by action-reaction. In this context the study of markets with consumer switching costs has cast some doubts onto the generality of increasing dominance. For instance, in Beggs-Klemperer [1989] the evolution of market structure is shown to be characterized by action-reaction. Propositions 1 and 2 above support Beggs-Klemperer's result since in expected terms action-reaction describes the equilibrium evolution of the market.

Our model differs from Beggs-Klemperer's in several respects. In Beggs-Klemperer market shares evolve monotonically and deterministically in the direction of decreasing dominance at a high speed. On the contrary, in our model, the evolution of the market is stochastic rather than deterministic. Furthermore, it need not be monotonically decreasing but it depends on the particular values of $\mu, \phi$. So, for instance, the market is stationary when either $\mu=\phi=1$, or $\mu=0$, or finally $\phi=0$. However, for values of $\mu, \phi \in(0,1)$ we should expect the market share of the largest firm to fall since the largest firm charges a higher expected price. Hence action-reaction is expected to hold in equilibrium. It is obvious however that the stochastic nature of our equilibrium makes increasing dominance a perfectly possible though much less probable outcome ${ }^{8}$. 
V.3. Price wars and sales in markets with switching costs

Klemperer [1989] constitutes the first study of the incidence of price wars in markets with consumer switching costs. In our model price wars are found to be pervasive in this type of market. Our model differs from Klemperer's in some important points. Klemperer considers a dominant firm versus a fringe of competitors competing in quantities. Price wars are triggered by entry of new competitors joining the competitive fringe. On the contrary, we consider an oligopolistic market in which no firm acts as a Stackelberg leader, and firms compete in prices. Price wars are endogenously driven by the own dynamics of price competition in these markets. Price wars are represented by low realizations of the equilibrium mixed strategies of the duopolistic firms and therefore may be thought to constitute an accidental but recurrent phenomenon in markets with switching costs. Such low realizations of the mixed strategy equilibrium of our model could be alternatively interpreted as endogenous sales, or price promotions.

Price promotions or deals are short-term price cuts offered to the consumer. This is a widespread pricing policy that has received subsantial attention in the marketing literature. Theoretically, several studies, among which Varian [1980] is probably the most representative, have also dealt with this pricing policy. However, as Raju [1986] points out, these models do not explain the existence of differences in size and frequency with which promotions occur across different firms producing a homogenous good. An additional drawback of existing models of price promotions is their static nature despite of the dynamic character of promotions. Firms offer price discounts today to increase current and more generally future demand. This can only be reflected in a model with explicit consumer loyalties like ours. 
In the terminology of the marketing literature, we call regular price to the uppermost price charged by each firm $\left(\mathrm{p}_{\mathrm{r}}\right.$, in our model.) Any price below $\mathrm{p}_{\mathrm{r}}$ named with positive density, is known as the discounted price. The (expected) size of the discount a firm offers is thus equal to the difference between the regular price and the expected discounted price. In our model, the latter is an increasing function of firm's market share. Hence, we predict an inverse relationship between the size of the discount and firm's market share. Similarly, the frequency with which discounts are offered is inversely related to market share. This is clear since small firms offer prices below the uppermost price with larger probability (i.e. frequency.) Our model thus fits some of the existing evidence on price promotions (Raju 1986.)

\section{Extensions}

\section{VI.1. Growing demand}

In this section we analyze the effects of growing demand on first and second period competition. In the second period although qualitatively the equilibrium is similar to the case of stationary demand, prices are lower and profits higher. In the first period, the result is ambiguous.

Consider the model of previous sections but now assume that the total number of consumers is not in steady state but instead is growing at a positive rate $\mu(\gamma-1)$ where $\gamma>1$. While the expected outflow of consumers remains at $\mu \mathrm{N}$, the corresponding inflow is now multiplied by $\gamma$ and hence the total number of consumers in the second period is given by $\mathrm{N}(1+\mu(\gamma-1))$. Again we have three types of consumers in the second period but their relative proportions are now changed. The expected proportions of old consumers, new fully informed consumers and, partially informed consumers are $(1-\mu)$, 
$\gamma \mu \phi$ and, $\gamma \mu(1-\phi)$ respectively. Notably, both the ratio of new to old consumers and, the ratio of price sensitive to price insensitive consumers increase with $\gamma$.

The mere introduction of growing demand does not modify the main charateristics of the equilibrium of the second period subgame ${ }^{9}$. The solution of this problem is identical to that of the original one, where demand was in steady state, if the discount factor is multiplied by $\gamma / \theta$ and the proportion of new consumers $\mu$ is multiplied by $\theta$ $(\theta=\gamma /[1+\mu(\gamma-1)])^{10}$.

Second period prices are thus lower because now demand growth reduces the proportion of locked-in old consumers. There are two effects of an increase in $\gamma$ on second period expected profits. First, for given prices, profits increase because of the absolute increase in total demand. Second, as we have just been discussing, competition is more intense which has a negative effect on profits. Both effects can be found in equation (11) below. The first term between brackets constitutes precisely the increase in profits due to the market expansion. The second term in the brackets reflects the decrease in profits due to increased competition. For $\mu, \phi \in(0,1)$, the first effect dominates the second since imperfect information about firms' prices limit the extent to which competition is strengthen when the market expands.

$$
\begin{gathered}
\partial \Pi_{\mathrm{j} 2} / \partial \gamma=\mathrm{p}_{\mathrm{r}}\left[[\mu(1+\phi) \mathrm{N} / 2] \frac{(1-\mu) \mathrm{x}_{11}+\mu \gamma(1-\phi) \mathrm{N} / 2}{(1-\mu) \mathrm{x}_{11}+\mu \gamma(1+\phi) \mathrm{N} / 2}\right. \\
-\left[\mu(1-\mu) \phi \mathrm{x}_{11} \mathrm{~N}\right] \frac{(1-\mu) \mathrm{x}_{\mathrm{j} 1}+\mu \gamma(1+\phi) \mathrm{N} / 2}{\left.\left[(1-\mu) \mathrm{x}_{11}+\mu \gamma(1+\phi) \mathrm{N} / 2\right]^{2}\right] \geq 0 \forall \mathrm{j}}
\end{gathered}
$$


Whereas market expansion generates, in general terms, fiercer competition in the second period, its effect in the first period is ambiguous. First, accumulating a large market share is less attractive since the proportion of new uncommitted consumers in the second period is larger when market demand grows over time. However, the increased importance of the future means that firms would compete more vigorously for future profits which tends to lower prices. Therefore the final effect will depend on the particular values of $\gamma$ and $\phi$. For instance, for $\phi$ close to zero the second effect is expected to dominate since second period profits are higher. However, for $\phi$ equal to one, the first effect is likely to dominate since firms will generally values less their market shares.

\section{VI.2. Entry deterrence}

To consider the possibility of entry deterrence our game is now modified as follows. In period one, only firm one enters the market. This firm decides the number the consumers to be served, that is $x_{11}$ in our context. In the second period a potential entrant considers whether to enter the market or not. If it does, it faces a positive cost of entry, $\mathbf{k}$.

For $\mu=0$, entry is clearly blockaded since all consumers are locked-in the firms they were previously patronizing. On the contrary, in a market without switching costs, $\mu=1$, entry can never be profitably deterred. In these two cases the incumbent firm will sell to all consumers, $\mathrm{x}_{11}=\mathrm{N}$. For $0<\mu<1$, a firm will be willing to enter if its expected profits are larger than the fixed costs of entry it has to pay. The expected profits of the potential entrant equal $\mathrm{p} \mu \mathrm{N}$ where $\mathrm{p}$ is an increasing function of the

market share of the incumbent, $x_{11}$. Therefore the larger the market share of the 
incumbent the more likely is entry. An incumbent with a large customer base would prefer to milk its customer base rather than to try to deter entry. When the fixed costs of entry are large enough, there exists a level of incumbent's market share such that for any market share smaller than that entry is deterred. Formally,

Proposition 5. For $\mu \in(0,1)$ and for all $k>k^{*}$, there exists $\bar{x}_{11}$ such that for all $x_{11}$ smaller than $\bar{x}_{11}$, entry is never profitable.

Notice that $\bar{x}_{11}$ is increasing in $\mathrm{k}$ as the common sense would suggest. When fixed costs are large, the incumbent may deter entry simply commiting to sell to a maximum of $\overline{\mathbf{x}}_{11}$ consumers at the reservation price in the first period. It is possible to find values of the discount factor $\delta$ not too small such that the incumbent prefers to commit to a low market share, that is to sell to a smaller number of consumers in the first period than maximize total profits taking the entrant's behaviour as given, in order to deter entry. For smaller values of $\delta$ the incumbent will always sell to all first period consumers (i.e. $\mathrm{N})^{11}$.

\section{VI.3. Word-of-mouth externalities.}

In this subsection we modify the informational setting we have been using thorought the paper to account for word-of-mouth externalities. Diamond [1989] distinguishes four different mechanisms of information gathering: sequential search, price guides, advertising and finally, word-of-mouth. The latter reflecting the fact that some information is transmitted freely through the random contacts of informed and uninformed agents. In previous sections we assumed an information mechanism where $\phi$ consumers freely acquired a price guide to lowest cost shopping, while the remaining 
$1-\phi$ found that price guide prohibitively costly. These uninformed consumers were then assumed to split evenly across competing firms. Now the rate of arrival of uninformed consumers to a given firm is assumed to be a direct function of the firm's market share. It should be uncontroversial that information transmission through random contacts between informed and uninformed consumers is more likely to be in the benefit of a firm the larger is its customer base. With this assumption we try to capture the (previously) discussed fact that some information passes between consumers in a costless way (see Sutton 1980.) This is, we believe, a natural way of modelling word-of mouth externalities 12 .

Let $\theta_{j}$ be the proportion of all uninformed consumers who purchase from firm $j$, $\theta_{1}+\theta_{2}=1$. For simplicity, we assume that $\theta_{\mathrm{j}}$ equals firm j's first-period market share $\mathbf{x}_{\mathbf{j} 1} / \mathrm{N}$. Under this assumption, the proportion of total demand captive in the largest firm is now relatively increased for any given price, which generates a greater incentive to exploit price-insensitive consumers. Consequently, the largest firm names a higher (expected) price which makes it possible for the smallest firm to raise its (expected) price without loosing demand. Therefore, second-period prices increase on average. On the contrary, first-period competition is encouraged. Prices fall because word-of-mouth externalities introduce an extra-incentive to obtain market share 1314 . As in section $\mathrm{V}$, we measure the overall competitive effect of switching costs with the help of total profits. In the presence of word-of-mouth externalities, switching costs inequivocally make the market less competitive. 


\section{Conclusions}

In this paper we have developed a simple specification of consumer switching costs that results naturally in firms having asymmetric market shares. Most previous results in two period models of switching costs have been derived in our model in a more natural framework. More importantly, we have found some clear support for action-reaction in the evolution of market share, accidental price wars, price promotions and the possibility of underinvesting in market share to deter entry when markets are characterized by the presence of consumer switching costs.

Our model can be extended in several directions. In particular, it is not hard in this model to allow for firms with different marginal costs. Similarly, the study of the private profitability of mergers in markets with switching costs can be easily undertaken as an extension of this model (see Padilla 1990b) ${ }^{15}$. Finally, further research to obtain a multi-period version of this anlysis is currently being undertaken.

\section{A.J. Padilla.}

Nuffield College.

Oxford OX1 1NF. UK.

Notes.

1. A surveys of this literature can be found in Padilla [1990a].

2. Unfortunately, when $\phi=1$ the overall game has no Nash equilibrium at all. In fact, the best reply correspondence is not compact. Two ways of dealing with these problem could be either to look for correlated equilibria (which can be proved to exist) or similarly, to find the equilibrium of a more general game with an endogenous sharing rule as suggested by Simon-Zame [1990]. 
3. The existence of a mixed strategy equilibrium for the second period subgame can be easily guaranteed using the Dasgupta-Maskin [1986a] existence theorems for games with discontinuous payoffs.

4. It is easy to see that when $\mu \phi=0$, there is a NE in pure strategies where both firms charge the reservation price. On the other hand, when $\mu \phi=1$, the unique equilibrium of the game is characterized by each firm charging the marginal cost. Note in addition that the case where $\mu=1$ and $\phi \neq 0$ can be understood as the benchmark case of no switching costs. Equilibrium in this latter case involves mixed strategies as those characterized in proposition 1.

5. This is an important step in the constructive argument. In fact, when we deal with asymmetric games we cannot properly use a differential approach unless we are able to rule out interior mass points, what unfortunately is not likely to be the case.

6. Notice that $\mathrm{p}^{*}$ may be negative, that is firms may charge price below marginal costs during the first period of the game.

7. These results are equivalent to those in Farrell [1986] and Klemperer [1987a,b].

8. Some possible reasons why markets with consumer switching costs show action-reaction in equilibrium have been offered by Beggs-Klemperer [1989.] Among others, prices do affect current flow profits and thus make it cheaper for the follower to offer lower prices. Second, the presence of consumer turnover and fully informed consumers serve to erode increasing dominance.

9. See appendix B.

10. In this section, the proportions of old locked-in and new consumers are $(1-\mu) /(1+\mu(\gamma-1))$ and $\mu \gamma /(1+\mu(\gamma-1))$ respectively. In addition second period total demand is $(1+\mu(\gamma-1))$ times larger than first period demand. Therefore, the second period is now more valuable i.e. the effective discount factor increases by $(1+\mu(\gamma-1)$.) 
11. In our model, given the inelastic character of consumer demand, accumulation of market share above the profit maximizing level in the absence of entry will never be a profitable strategy.

12. An alternative modelling strategy could be, following Diamond [1989]'s suggestion, to include price-reputations. In our model the two strategies are somewhat equivalent because the firm with the larger market share was the firm with the lowest prices in the previous period.

13. See appendix $\mathrm{C}$ for proofs of the results discussed in this section.

14. Notice that the difference between the second-period profits of the largest and smallest firm is now increased with respect to the case where no word-of-mouth externalities were assumed.

15. However, the extension to the case where consumers have rational expectations about future prices, and take expected second period prices into account in making first period purchase decisions, has proved untractable. 


\section{APPENDIX A.}

\section{Proof of Lemma 1.}

First, we show that ties can never occur in equilibrium. Notice that firms will never name prices above $p_{r}$ (since the associated level of profits equals zero) and/or prices below $\hat{\mathrm{p}}=\max _{\mathrm{j}} \hat{\mathrm{p}}_{\mathrm{j} 2}$, where $\hat{\mathrm{p}}_{\mathrm{j} 2}$ is such that $\mathrm{p}_{\mathrm{r}}\left[(1-\mu) \mathrm{x}_{\mathrm{j} 1}+\mu(1+\phi) \mathrm{N} / 2\right]\left(\hat{\mathrm{p}}_{12} \geq \hat{\mathrm{p}}_{22}\right.$ given $\mathrm{x}_{11} \geq \mathrm{x}_{21}$. $)$ Assume now that both firms choose the same price $\mathrm{p} / \hat{\mathrm{p}} \leq \mathrm{p} \leq \mathrm{p}_{\mathrm{r}}$. This cannot be an equilibrium because both firms will prefer to undercut by an $\epsilon>0$ sufficiently small and thus increase profits by capturing all fully informed consumers.

The proof is then completed by showing that there is no pure-strategy equilibrium in which all players name different prices. Assume $\mathrm{p}_{12}<\mathrm{p}_{22}$, then firm 1 will do better by raising its price by an $\epsilon>0$. QED.

\section{Proof of Lemma 2.}

It is fairly obvious. For $\mathrm{p} \geq \mathrm{p}_{\mathrm{r}}$, demand and therefore profits are zero. Therefore $\Pi_{j 2}(p)<\Pi_{j 2}\left(p_{r}\right)$ for all j. QED.

\section{Proof of Lemma 3.}

Take $\hat{\mathrm{p}}_{\mathrm{j} 2}$ as defined in the proof of Lemma 1. $\hat{\mathrm{p}}_{\mathrm{j} 2}$ is the lowest price firm $\mathrm{j}$ is willing to pay in order to be the lowest-priced firm. For any $\mathrm{p}<\hat{p}_{j 2}, \Pi_{j 2}(p)<\Pi_{j 2}\left(p_{r}\right)$ and therefore $p$ cannot be named with positive density. QED. 


\section{Proof of Lemma 4.}

(a) Given our assumptions about the upper bounds of supp $\xi_{12}$ and supp $\xi_{22}$, $\xi_{12}\left(\overline{\mathrm{p}}_{12}\right)=1$. Hence $\Pi_{12}\left(\overline{\mathrm{p}}_{12}\right)$ is strictly increasing in its argument and it attains a maximum at $\mathrm{p}_{\mathrm{r}}$. Then the level of profits in equilibrium has to be equal to $\pi_{12}\left(\mathrm{p}_{\mathrm{r}}\right)=\hat{\mathrm{p}}_{12}\left[(1-\mu) \mathrm{x}_{11}+\mu(1+\phi) \mathrm{N} / 2\right]$ as it can be easily checked by substituting $\hat{\mathrm{p}}_{12}$ by its value.

(b) Suppose $\underline{p}_{i 2}<\underline{p}_{j 2}$, then $\left.\Pi_{j 2} \underline{p}_{i 2}\right)$ increases for values of $p$ such that $\underline{p}_{i 2}<p \leq \underline{p}_{j 2}$ since $\xi_{j 2}(p)$ is constant for prices in that interval. Therefore this configuration could only constitute an equilibrium if $\underline{\mathrm{p}}_{\mathrm{i} 2}=\mathrm{p}_{\mathrm{r}}$ but $\underline{\mathrm{p}}_{\mathrm{i} 2}<\overline{\mathrm{p}}_{12}=\mathrm{p}_{\mathrm{r}}$. Hence $\underline{\mathrm{p}}_{\mathrm{i} 2}=\underline{\mathrm{p}_{\mathrm{j} 2}}=\underline{\mathrm{p}}$. Suppose now that the largest firm (e.g.firm 1) names $\mathrm{p}$ with positive probability. Then the other firm could by undercutting $\mathrm{p}$ by an $\epsilon>0$ strictly increase its profits. (It could sell $\mu \phi \mathrm{N}$ more consumers at only a sligthly smaller price.) Thus firm 1 will name $\mathrm{p}$ with zero probability. Similarly, if firm 2 names $\mathrm{p}$ with positive probability, $\Pi_{12}(\underline{p}-\epsilon)>\Pi_{12}(\underline{p}+\epsilon)$. Therefore, in equilibrium no firm names $\underline{p}$ with positive probability.

(c) In equilibrium $\Pi_{\mathrm{j} 2}(\mathrm{p})=\pi_{\mathrm{j} 2}$ constant for all $\mathrm{p}$ in supp $\xi_{\mathrm{j} 2} \mathrm{j}=1$, 2. From (a) $\Pi_{12}=\hat{\mathrm{p}}_{12}\left[(1-\mu) \mathrm{x}_{11}+\mu(1+\phi) \mathrm{N} / 2\right]$. Hence $\underline{\mathrm{p}}=\hat{\mathrm{p}}_{12}$.

(d) If $\mathrm{x}_{21}>\mathrm{x}_{11}$, then $\hat{\mathrm{p}}_{22}>\hat{\mathrm{p}}_{12}$ which contradicts either (b) or (c).

(e) Immediate from the definition of NE and (b) and (c) above. QED.

\section{Proof of Proposition 1.}

Lemmata 1 to 4 above and points (a)-(d) in the text guarantee the existence of an equilibrium satisfying all conditions in Lemma 4 , when firms use $\xi_{12}, \xi_{22}$ (as defined in equation (4)) respectively. Each firm is by contruction indifferent among prices in its 
support. For prices outside the support profits are always smaller as it was shown in Lemma 4. QED.

\section{Proof of Corollary 1.}

We first prove the following Lemma:

Lemma 5. If $x_{11} \geq x_{21}$ then, either $\bar{p}_{12} \geq \bar{p}_{22}$ or $\bar{p}_{12}=\bar{p}_{22}$ and $\bar{p}_{22}$ is not named with positive probability.

Proof. (By contradiction.) Otherwise, either (a) $\overline{\mathrm{p}}_{12}=\overline{\mathrm{p}}_{22}$ and both are named with positive probability or (b) $\overline{\mathrm{p}}_{22} \geq \overline{\mathrm{p}}_{12}$ or $\overline{\mathrm{p}}_{12}=\overline{\mathrm{p}}_{22}$ and $\overline{\mathrm{p}}_{12}$ is not named with positive probability. (a) cannot occur in equilibrium since there cannot be simultaneous mass points in both equilibrium distribution functions. Consider that firm 1 names $\bar{p}$ with positive probability, $\tau>0$. Since the number of mass points has to be countable, there exists an $\epsilon>0$ such that $\overline{\mathrm{p}}-\epsilon$ is named with probability zero. Then if firm 2 names $\overline{\mathrm{p}}-\epsilon$ with probability $\tau$ and $\overline{\mathrm{p}}$ with zero probability, $\Pi_{22}(\overline{\mathrm{p}}-\epsilon)>\Pi_{22}(\overline{\mathrm{p}})$ which contradicts the possibility of an equilibrium. The proof is then completed by noting that if (b) is true, then $x_{21} \geq x_{11}$ which contradicts our initial assumption. QED.

Therefore, Lemma 4 describes certain properties of the support of the equilibrium strategies to be satisfied for all equilibria. It also pins down the level of profits of both firms in any such equilibrium. QED. 


\section{Proof of Proposition 2.}

We heavily rely on Osborne-Pitchick(1986). A more formal proof of uniqueness for games isomorphic to ours can be found in their paper. Following these authors, the equilibrium described in proposition 1 is unique provided that; (a) $d(p)$, aggregate demand at price $p$, is left-continuous and nonincreasing in $p$; (b) there exists $p_{0}>0$ such that $d(p)=0$ for all $\mathrm{p} \geq \mathrm{p}_{\mathrm{o}}$ and $\mathrm{d}(\mathrm{p})>0$ for all $\mathrm{p}<\mathrm{p}_{0}$; and $(\mathrm{c}) \mathrm{pd}(\mathrm{p})$, total industry profits, are concave in $\mathrm{p}$. Such conditions are trivially satisfied for our second-period subgame. Uniqueness thus follows. QED.

\section{Proof of Lemma 6.}

Identical to Lemma 1.

\section{Proof of Proposition 3.}

Identical to proposition 1 , using Lemma 7 and 8 , and the constructive argument in the text.

\section{Proof of Proposition 4.}

Existence has been shown in the previous proposition. Therefore we just need to prove uniqueness. First, we prove that the equilibrium in proposition 3 is the unique symmetric equilibrium of the overall game. For that we need the following Lemmata, 
Lemma 9.1. There are no mass points in the symmetric equilibrium strategies.

Proof. In any symmetric equilibrium both firms use the same pricing strategy defined by an identical distribution function over a coincident support. For any price $\mathrm{p}$ in that common support, no firm will name $\mathrm{p}$ with positive probability. Otherwise since the number of mass points has to be countable, there exists $\epsilon>0$ such that $\mathrm{p}-\epsilon$ is named with zero probability. However, this cannot be an equilibrium strategy because the other firm will deviate, naming $\mathrm{p}-\epsilon$ with positive probability and $\mathrm{p}$ with zero probability. The deviant firm increases its profits for $\epsilon>0$ sufficiently small. QED.

Lemma 9.2. The (common) support of any symmetric equilibrium is connected (i.e., there are no gaps in the support.)

Proof. Recall that a set is said to be connected if it is not the union of two non-empty, disjoint closed subsets. In particular a subset of $\mathbb{R}$ is connected iff it is an interval. Let $\left(\mathrm{p}_{\mathrm{a}}, \mathrm{p}_{\mathrm{b}}\right)$ be the largest gap in the support of the equilibrium strategy $\Omega(\mathrm{p})$. Let $\left\{\mathrm{p}_{\mathrm{s}}\right\},\left\{\mathrm{p}_{\mathrm{t}}\right\}$ be two sequences of prices converging to $\mathrm{p}_{\mathrm{a}}, \mathrm{p}_{\mathrm{b}}$ respectively. Since we already know from Lemma 9.1 that $\Omega(p)$ is atomless, $\underset{p \rightarrow p_{a}}{\lim } \Omega\left(p_{s}\right)=\underset{p \rightarrow p_{b}}{\lim } \Omega\left(p_{t}\right)$ which in turn implies $p_{a}=p_{b}$. QED.

To show that there are no asymmetric equilibria, following Osborne-Pitchick [1986], it is sufficient that both $\Pi_{f}(p), \Pi_{s}(p)$ differ from $\pi_{1}$ for some $p_{f}, p_{s} \in[p, p]$ respectively to guarantee that no degenerancies (mass points and/or gaps in the support) exist in equilibrium. This is true for our game as it can be observed in equations (6), (7) and the definition of $\pi_{1}$. QED. 


\section{Proof of Proposition 5.}

It is enough to see that $\mathrm{k}^{*}=\mathrm{p}_{\mathrm{r}} \mu(1-\phi)^{2} \mathrm{~N} /(1+\phi)$ and that $\overline{\mathrm{x}}_{11}=\max \left\{\mathrm{N},[\mu \mathrm{N} / 2(1-\mu)]\left[\left(\mathrm{k}(1+\phi)-\mathrm{p}_{\mathrm{r}} \mu \mathrm{N}(1-\phi)\right) /\left(\mathrm{p}_{\mathrm{r}} \mu \mathrm{N}-\mathrm{k}\right)\right]\right\} . \mathrm{QED}$.

\section{APPENDIX B.}

When the demand grows over time at a positive rate $\mu(\gamma-1), \gamma>1$ (see section VI.1.), second period profits are given by

$$
\mathrm{p}_{\mathrm{r}}\left[(1-\mu) \mathrm{x}_{\mathrm{j} 1}+\gamma \mu(1-\phi) \mathrm{N} / 2\right] \mathrm{j}=1,2 \text {. }
$$

The equilibrium pricing strategy of firm $\mathrm{j}$ is equal to

$$
\xi_{\mathrm{j} 2}(\mathrm{p})=(\mathrm{p}-\underline{\mathrm{p}})\left[(1-\mu) \mathrm{x}_{\mathrm{k} 1}+\gamma \mu(1+\phi) \mathrm{N} / 2\right] / \mathrm{p} \gamma \mu \phi \mathrm{N} .
$$

where $\mathrm{p}=\mathrm{p}_{\mathrm{r}}\left[(1-\mu) \mathrm{x}_{11}+\gamma \mu(1-\phi) \mathrm{N} / 2\right] /\left[(1-\mu) \mathrm{x}_{11}+\gamma \mu(1+\phi) \mathrm{N} / 2\right]$.

Notice that $\partial \mathrm{p} / \partial \gamma<0$.

Similarly, first period profits are equal to

$$
\begin{gathered}
(1-\phi) \mathrm{p}_{\mathrm{r}}+\delta \mathrm{p}_{\mathrm{r}}\left[(1-\mu) \mathrm{x}_{\mathrm{j} 1}+\gamma \mu(1-\phi) \mathrm{N} / 2\right] \\
=(1-\phi) \mathrm{p}_{\mathrm{r}}+\delta^{*} \mathrm{p}_{\mathrm{r}}\left[\left(1-\mu^{*}\right) \mathrm{x}_{\mathrm{j} 1}+\mu^{*}(1-\phi) \mathrm{N} / 2\right]
\end{gathered}
$$


where $\delta^{*}=\delta \gamma / \theta$ and $\mu^{*}=\mu \theta . \theta=\gamma /[1+\mu+(\gamma-1)]$.

Finally, the symmetric equilibrium pricing strategy in period one is equal to

$$
\Omega(\mathrm{p})=1-\left\{(1-\phi)\left(\mathrm{p}_{\mathrm{r}}-\mathrm{p}\right) /\left[2 \phi\left(\mathrm{p}+\delta^{*} \mathrm{p}^{\prime \prime}\left(1-\mu^{*}\right)\right]\right\}\right.
$$

where $\mathrm{p}^{\prime \prime}=\mathrm{p}_{\mathrm{r}}\left\{\left[\left(1-\mu^{*}\right)(1+\phi)+\mu^{*} \gamma(1-\phi)\right] /\left[\left(1-\mu^{*}\right)(1+\phi)+\mu \gamma(1+\phi)\right]\right\} ;$ decreasing in $\gamma$.

Notice that $\partial \Omega(\mathrm{p}) / \partial \delta>0$ and $\partial \Omega(\mathrm{p}) / \partial \mu<0$ for all $\mathrm{p}$.

\section{APPENDIX C.}

second period.

Second period profits are now equal to,

$$
\Pi_{\mathrm{j} 2}=\mathrm{p}\left[\mathrm{A}(\mu, \phi)+\mu \phi\left(1-\xi_{\mathrm{k} 2}(\mathrm{p})\right) \mathrm{N}\right]
$$

where $\mathrm{A}(\mu, \phi)=1-\mu \phi$. Then, using the same procedure of section III, we obtain

$$
\xi_{\mathrm{k} 2}{ }^{*}(\mathrm{p})=\left[\left(\mathrm{p}^{*}{ }^{*}\right)\left(\mathrm{x}_{\mathrm{j} 1} \mathrm{~A}(\mu, \phi)+\mu \phi \mathrm{N}\right) / \mathrm{p} \mu \phi \mathrm{N}\right]
$$

where $\underline{\mathrm{p}}^{*}=\left(\mathrm{p}_{\mathrm{r}} \mathrm{x}_{11} \mathrm{~A}(\mu, \phi)\right) / \mu \phi \mathrm{N}$.

It is then possible to see by direct comparison that for all $\mathrm{p}$, for all $\mathrm{k}=1,2$, $\xi_{\mathrm{k} 2}{ }^{*}(\mathrm{p})<\xi_{\mathrm{k} 2}(\mathrm{p})$ and $\underline{\mathrm{p}}^{*}>\underline{\mathrm{p}}$ so that both firms charge now higher prices with greater probability. 


\section{.first period.}

Both firms are assumed to be identical ex-ante. Therefore in the first period uninmformed consumers are distributed evenly between them. Let $\bar{\Pi}$ be the second-period profits of the large firm, and similarly $\underline{\Pi}$ be the corresponding profits for the small firm. In equilibrium each firm names profits according to

$$
\Omega(p)=1-\frac{(1-\phi)\left(p_{\mathrm{r}}-\mathrm{p}\right) \mathrm{N} / 2}{\mathrm{p} \phi \mathrm{N}+\delta(\bar{\Pi}-\underline{\Pi})}
$$

where $\bar{\Pi}-\underline{\Pi}=\underline{\mathrm{p}} *\left[\left(\mathrm{x}_{11}-\mathrm{x}_{21}\right) \mathrm{A}(\mu, \phi)\right]$. Hence,

$$
\Omega^{*}(\mathrm{p})>\Omega(\mathrm{p}) \forall \mathrm{p}
$$

Total profits are

$$
\pi^{*}=\mathrm{p}_{\mathrm{r}}\left\{(1-\phi)+\delta\left(\mathrm{A}^{2}(1+\phi) / \mu \phi\right)\right\} \mathrm{N} / 2
$$

Hence,

$$
\partial \pi^{*} / \partial \mu<0 \text { for all } \mu \in(0,1) \text {. }
$$




\section{References.}

Beggs.A. and P.Klemperer(1989) "Multiperiod Competition with Switching Costs." Nuffield D.P. 45. Oxford.

Budd.C, Harris.C.J. and J.Vickers(1990) "A Model of the Evolution of Duopoly: Does the Asymmetry between Firms Tend to Increase or Decrease." Nuffield College. Oxford.

Dasgupta.P and E.Maskin(1986a) "The Existence of Equilibrium in Discontinuous Economic Games I:Theory." Review of Economic Studies. 53. pp.1-27.

Diamond.P(1989) "Search Theory." in Eatwell et al. (eds) Allocation, Information and Markets. MacMillan. London.

Farrell.J(1986) "A Note on Inertia in Market Share." Economic Letters. 21. pp.73-75. and C.Shapiro(1988) "Dynamic Competition with Switching Costs."

Rand Journal of Economics. 19. pp.123-137.

Harris.C.J(1988) "Dynamic Competition for Market Share: An Undiscounted

Model." Nuffield College. D.P. 35. Oxford.

Klemperer.P(1987a) "Markets with Consumer Switching Costs." Quarterly Journal of Economics. 102. pp.375-394. (1987b) "The Competitiveness of Markets with Consumer

Switching Costs." Rand Journal of Economics. 18. pp. 138-151. (1987c) "Entry Deterrence in Markets with Consumer Switching

Costs." Economic Journal Conference Supplement. pp.99-117. (1989) "Price Wars Caused by Switching Costs." Review of Economic Studies. 56. pp. 405-420. 
Kreps.D and J.Scheinkman(1983) "Quantity Precommittment and Bertrand Competition Yield Cournot Outcomes." Bell Journal of Economics. 14. pp.326-337.

Osborne,M.J. and C.Pitchik(1986) "Price Competition in a Capacity Constrained Duopoly." Journal of Economic Theory. 38. pp 238-260.

Padilla.A.J(1990a) "Consumer Switching Costs: A Survey." Nuffield College. Oxford.

(1990b) "Bertrand Competition and Consumer Switching Costs Yield Cournot Outcomes." Nuffield College. Oxford.

Raju.J.S(1986) "A Theory of Price Promotions." Stanford University. mimeo.

Shilony.Y(1977) "Mixed Pricing in Oligopoly." Journal of Economic Theory. 14. pp.373-388.

Simon,L.K and W.R.Zame(1990) "Discontinuous Games and Endogenous Sharing Rules." Econometrica. 50. pp.861-872.

Sutton.J(1980) "A Model of Stochastic Equilibrium in a Quasicompetitive Industry." Review of Economic Studies. 47. pp.705-722.

Varian.H(1980) "A Model of Sales." American Economic Review. pp.651-659.

Weizsacker.C von(1984) "The Costs of Substitution." Econometrica. 52. pp.1085-1116. 


\section{PUBLISHED ISSUES}

\section{FIRST PERIOD}

1

3

"A Metatheorem on the Uniqueness of a Solution"

T. Fujimoto, C. Herrero. 1984.

"Comparing Solution of Equation Systems Involving Semipositive Operators"

T. Fujimoto, C. Herrero, A. Villar. February 1985.

"Static and Dynamic Implementation of Lindahl Equilibrium"

F. Vega-Redondo. December 1984.

"Efficiency and Non-linear Pricing in Nonconvex Environments with Externalities"

F. Vega-Redondo. December 1984.

"A Locally Stable Auctioneer Mechanism with Implications for the Stability of General Equilibrium Concepts"

F. Vega-Redondo. February 1985.

"Quantity Constraints as a Potential Source of Market Inestability: A General Model of Market Dynamics"

F. Vega-Redondo. March 1985.

"Increasing Returns to Scale and External Economies in Input-Output Analysis"

T. Fujimoto, A. Villar. 1985.

"Irregular Leontief-Straffa Systems and Price-Vector Behaviour"

I. Jimenez-Raneda / J.A. Silva. 1985.

"Equivalence Between Solvability and Strictly Semimonotonicity for Some Systems Involving Z-Functions"

C. Herrero, J.A. Silva. 1985.

"Equilibrium in a Non-Linear Leontief Model"

C. Herrero, A. Villar. 1985.

"Models of Unemployment, Persistent, Fair and Efficient Schemes for its Rationing"

F. Vega-Redondo. 1986.

"Non-Linear Models without the Monotonicity of Input Functions"

T. Fujimoto, A. Villar. 1986.

"The Perron-Frobenius Theorem for Set Valued Mappings"

T. Fujimoto, C. Herrero. 1986.

"The Consumption of Food in Time: Hall's Life Cycle Permanent Income Assumptions and Other Models"

F. Antoñazas. 1986.

"General Leontief Models in Abstract Spaces"

T. Fujimoto, C. Herrero, A. Villar. 1986. 


\section{SECOND PERIOD}

WP-AD 90-01 "Vector Mappings with Diagonal Images"

C. Herrero, A.Villar. December 1990.

WP-AD 90-02 "Langrangean Conditions for General Optimization Problems with Applications to Consumer Problems"

J.M. Gutierrez, C. Herrero. December 1990.

WP-AD 90-03 "Doubly Implementing the Ratio Correspondence with a 'Natural' Mechanism"

L.C. Corchón, S. Wilkie. December 1990.

WP-AD 90-04 "Monopoly Experimentation"

L. Samuelson, L.S. Mirman, A. Urbano. December 1990.

WP-AD 90-05 "Monopolistic Competition : Equilibrium and Optimality"

L.C. Corchón. December 1990.

WP-AD 91-01 "A Characterization of Acyclic Preferences on Countable Sets"

C. Herrero, B. Subiza. May 1991.

WP-AD 91-02 "First-Best, Second-Best and Principal-Agent Problems"

J. Lopez-Cuñat, J.A. Silva. May 1991.

WP-AD 91-03 "Market Equilibrium with Nonconvex Technologies"

A. Villar. May 1991.

WP-AD 91-04 "A Note on Tax Evasion"

L.C. Corchón. June 1991.

WP-AD 91-05 "Oligopolistic Competition Among Groups"

L.C. Corchón. June 1991.

WP-AD 91-06 "Mixed Pricing in Oligopoly with Consumer Switching Costs" A. Jorge Padilla. June 1991. 